\title{
UTJECAJ MATIČNOG SUPSTRATA NA FIZIČKE I MINERALNE ZNAČAJKE TLA U PARKU PRIRODE MEDVEDNICA
}

\section{THE EFFECT OF PARENT MATERIAL ON PHYSICAL AND MINERAL SOIL PROPERTIES ON MEDVEDNICA NATURE PARK}

\author{
Ivan PERKOVIĆ1, Nikola PERNAR1', Darko BAKŠIĆ', Nikola GLAMOČLIJA², Vibor ROJE*
}

\begin{abstract}
Sažetak
Matični supstrat, uz klimu, reljef, organizme i vrijeme, predstavlja jedan od pet glavnih pedogenetskih čimbenika. S pedogeneskog stajališta najvažnija su svojstva matičnog supstrata: mineralni i kemijski sastav, način i intezitet trošenja te sadržaj biogenih elemenata. Cilj ovog rada je utvrditi utjecaj različitih matičnih supstrata na fizičke i mineralne značajke tla. Na području PP Medvednice na šest različitih litoloških cjelina otvoreno je 80 pedoloških profila: metamorfne stijene - dominantno škriljavci, metamorfne stijene - dominantno filiti, magmatske stijene, pješčenjaci, lapori i lakotrošivi vapnenci. Uzorci tla uzeti su po horizontima, a analizirani su oni iz humusnoakumulatinog (A-horizont) i B-horizonta. Određeni su sljedeći parametri: debljina horizonata, dubina profila, udjel skeleta, garnulometrijski sastav tla, postojanost strukturnih mikroagregata i mineralni sastav tla (XRD) metodom rendgenske difrakcije. Rezultati istraživanja pokazuju da postoje statistički značajne razlike između različitih litoloških cjelina za sve promatrane varijable osim debljine horizonata. Najveće dubine tla su povrh laporovitih stijena, a najmanje na dolomitiziranim vapnencima, što je ponajprij uvjetovano načinom trošenja matičnog supstrata. Na svim istraživanim litološkim cjelinama, tla na području PP Medvednice vrlo su postojanih mikroagregata. U odnosu na B-horizont u humusnoakumulativnom horizontu utvrđena je veća postojanost strukturnih mikroagregata. Tla povrh lakotrošivih vapnenaca imaju statistički veći veći udjel gline i manji udjel krupnog i sitnog pijeska od tla ostalih litoloških cjelina. Za sve litološke cjeline teksturna oznaka najčešće je u rasponu od praškaste do glinaste ilovače, dok je na litološkoj cjelini povrh vapnenaca udjel gline statistički značajno veći, pa je teksturna oznaka u rasponu od praškaste glinuše do glinuše. Litološke cjeline povrh magmatskih i metamorfnih stijena imaju statistički značajno manji udjel minerala kvarca i veći udjel minerala klorita i feldspata u odnosu na sedimentne stijene.
\end{abstract}

KLJUČNE RIJEČl: matični supstrat, litološka cjelina, fizičke i mineralne značajke tla, PP Medvednica

\section{UVOD}

\section{INTRODUCTION}

Matični supstrat, uz klimu, reljef, organizme i vrijeme, predstavlja jedan od pet pedogenetskih čimbenika (Jenny, 1941, reprinted 1994). Niti jedan pedogenetski čimbenik ne bi trebalo promatrati samostalno, nego u određenoj konstela- ciji s drugim čimbenicima. Zbog toga je svako svojstvo tla funkcija pet gore navedenih pedogenetskih čimbenika: $s=$ $\mathrm{f}(\mathrm{k}, \mathrm{o}, \mathrm{r}, \mathrm{ms}, \mathrm{v}$.....), gdje je: $\mathrm{s}$ - svojstvo; $\mathrm{k}$ - klima, o - organizmi, $r$ - reljef, ms - matični supstrat, $v$ - vrijeme. Prema Bradyju (1990) pedogenetski čimbenici predstavljaju nezavisne varijable koje u raznim kombinacijama utječu na razvoj i svojstva tla. Od samih početaka razvoja pedologije

\footnotetext{
${ }^{1}$ dr. sc. Ivan Perković iperkovic@sumfak.hr, prof. dr. sc. Nikola Pernar npernar@sumfak.hr, izv. prof. dr. sc. Darko Bakšić dbaksic@sumfak.hr,

${ }^{2}$ Nikola Glamočlija, mag, ing. silv., nidzo47@hotmail.com, Zdenačka 132, Zdenci Brdovečki, 10291 Prigorje Brdovečko, doc. dr. Vibor Roje vroje@sumfak.hr, Sveučilište u Zagrebu, Sumarski fakultet, Zavod za ekologiju i uzgajanje šuma,Svetošimunska 25, Zagreb, Hrvatska
} 
kao znanosti, matični supstrat se predstavlja kao ključni pedogenetski čimbenik (Dokuchaev, 1883; Hilgard, 1906; Coffey, 1912). Bockheim et al. (2005) navode matični supstrat kao ključni pedogenetski čimbenik posebnto na regionalnoj razini, dok Birkeland (1999) navodi da je utjecaj matičnog supstrata izraženiji u sušim područjima.

S pedogeneskog stajališta najvažnija su svojstva matičnog supstrata: mineralni i kemijski sastav, način i intezitet trošenja te sadržaj biogenih elemenata. Matični supstrat izravno utječe na različita svojstva tla, kao što su tekstura, vodni kapacitet, kiselost, erodibilnost (Martinović, 2003). O utjecaju matičnog supstrata kao glavnog pedogenetskog čimbenika za razvoj i svojstva tla provedena su brojna istraživanja u različitim područjima (Brewer, 1954; Osher \& Boul, 1998; Burke, 2002; Olowolafe, 2002; Kooijman et al., 2005; Olatunji et al., 2007; Gökbulak \& Özcan, 2008; Badia et al., 2013). U Hrvatskoj su provedena istraživanja odnosa matičnog supstarat i tla, gdje su prikazani prevladavajući međusobni odnosi matičnog supstrata i pedotaksonomskih jedinica (Mar- tinović \& Vranković, 1997; Vrbek, 2009), međutim nisu provođena opsežnija istraživanja s ciljem utvrđivanja utjecaja matičnog supstrata na fizičke i mineralne značajke tla.

Područje Medvednice zbog svoje vrlo složene litološke građe i reljefnih značajki ima jako istaknut vegetacijski, mikroklimatski i pedofiziografski diverzitet. Kad se govori o kvaliteti izvornog materijala iz kojega nastaje tlo, u prvi plan dolaze stijene i njihove trošine, o čemu izravno ovisi fizička građa tla. Najbolji pokazatelji fizičke građe tla su njegova dubina, boja, skeletnost, granulometrijski sastav, gustoća tla, gustoća krute faze tla, ukupna poroznost, kapacitet za vodu, kapacitet za zrak, struktura te njegova hidraulička svojstva. Oni na Medvednici jako variraju i imaju glavnu ulogu u definiranju kvalitete tla, o čijem poznavanju ovisi uspješnost gospodarenja ekosustavom. Stoga je cilj ovog istraživanja utvrditi kako litološka podloga, odnosno matični supstrat utječe ponajprijo na fizičke (debljinu horizonata, dubinu profila, udjel skeleta, teksturu tla, strukturu tla) i mineralne značajke tla.

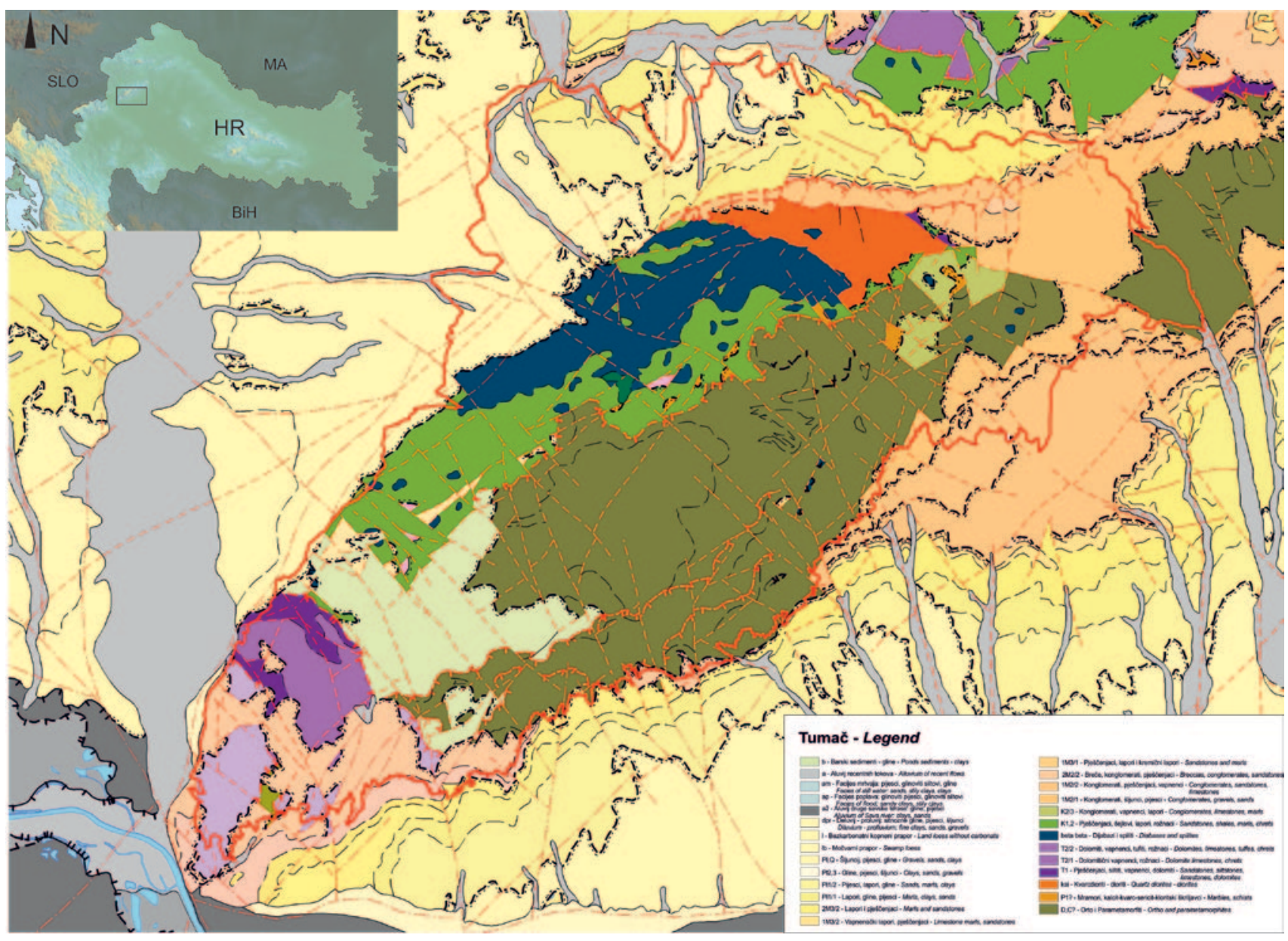

Slika 1. Područje istraživanja s geološkom kartom istraživanog područja: LIT1 (metamorfne stijene, dominantno zeleni škriljavci - D,C?; LIT2 (metamorfne stijene, dominantno filiti D,C?; LIT3 (magmatske stijene) - beta,beta; LIT4 (pješčenjaci) - K1,2 K2/3, 1M2/1; LIT5 (dominantno lapori) 1M2/1; LIT6 (litotamnijski vapnenci) - 2M2/2, 1M3/1, 1M3/2) - prema OGK 1:100000 (Basch 1983a; 1983b)

Figure 1. Research area with the geological map of the study area: LIT1 (metamorphic rocks, dominantly greenschists) - D,C?; LIT2 (metamorphic rocks, dominantly phyllites); D,C?; LIT3 (igneous rocks) - beta,beta; LIT4 (sandstones) - K1,2 K2/3, 1M2/1; LIT5 (clastic rocks, dominantly marls) 1M2/1; LIT6 (lithotamnic limestones) - 2M2/2, 1M3/1, 1M3/2) - according „OGK" 1:100000 (Basch 1983a; 1983b) 


\section{PODRUČJE ISTRAŽIVANJA} RESEARCH AREA

Istraživanja u radu obuhvatila su sjeverozapadno područje Hrvatske, odnosno Park prirode Medvednica (slika 1).

Centralni dio Medvednice (Zagrebačke gore) izgrađen je od paleozojskih i mezozojskih stijena različitog postanka koje su uklopljene u paleogenske, a poglavito u neogenske sedimentne stijene (Šikić, 1995). Paleozojske stijene koje su predstavljene ortometamorfitima i parametamorfitima obuhvaćaju najveći dio Parka prirode Medvednica i pružaju se od njegovog centralnog dijela u smjeru juga, jugoistoka i istoka sve do granica Parka. Pretežni dio ortometamorfita predstavljaju tipični zeleni škriljavci, dok su podređenije zastupljeni amfibolitski škriljavci, metagabri i metadijabazi (Pamić \& Injuk, 1986). Parametamorfiti su porijeklom sedimentne stijene nejednako zahvaćene regionalnom metamorfozom, tako da unutar njih nalazimo izmijenjene stijene od uškriljenih sedimenata, preko slejtova i filita do škriljavaca zone gornjih mikašista. Kompleks niskometamorfoziranih stijena pretpostavljene donjopermske starosti nalazi se na sjeveroistočnom dijelu Medvednice. Najčešći litološki član su različiti varijeteti rekristaliziranih vapnenaca i mramora s prijelazima u mramorne škriljavce. S mramornim škriljavcima izmjenjuju se kvarc-sericitni i kvarc-kloritni škriljavci. Stijene Mezozoika na Zagrebačkoj gori obuhvaćaju donjotrijaske klastite, srednje- i gornjotrijaske karbonate u kojima prevladavaju dolomiti i vapnoviti dolomiti, zatim kredne vulkanogeno-sedimentne stijene predstavljene dijabazima i spilitima, pješčenjacima, šejlovima, vapnencima, rožnjacima, brečama, konglomeratima, laporima i karbonatnim klastitima. Trijaske stijene zastupljene su u jugozapadnom dijelu PP Medvednice, a kredne u sjevernom, sjeverozapadnom i zapadnom. Neogenske, najvećim dijelom miocenske stijene protežu se rubnim dijelovima PP Medvednica, a predstavljene su konglomeratima, šljuncima, pijescima, organogenim i bioklastičnim vapnencima (litavcima), vapnovitim i glinovitim laporima i dr. (Šikić, 1995).

Prema podacima ranijih istraživanja (Vranković, 1973; Pernar et al., 2009; Vrbek, 2009; Bakšić et al., 2015) najzastupljenija tla na Medvednici su distrični kambisol, zatim eutrični kambisol, kalkokambisol, luvisol i rendzina. Prema Vrbeku (2009) na području parka prirode ukupno je utvrđeno 10 tipova tala, koji se pojavljuju u 25 podtipova, 19 varijeteta i 19 formi.

\section{MATERIJAL I METODE}

\section{MATERIAL AND METHODS}

Na području PP Medvednica otvoreno je 80 pedoloških profila ravnomjerno raspoređenih tako da obuhvate sve reprezentativne litološke cjeline. Uzeti su uzorci fizički iz- mijenjenog tla iz genetskih horizonata, kao i odlomak stijene odnosno matičnog supstrata radi određivanja litološke pripadnosti stijena. Analizirani su uzorci tla u humusnoakumulativnom (A-horizont) i prvom mineralnom hrizontu ispod humusnoakumulativnog horizonta (većinom B-horizont). Razlike između humosnoakumulativnog i B-horizonta su statistički analizirani po litološkim cjelinama. Priprema uzoraka (HRN ISO 11464, 2004) i analize izvršene su u laboratorijima Šumarskog fakulteta Sveučilišta u Zagrebu i Hrvatskog geološkog instituta u Zagrebu. Na terenu su prema FAO 2006 određeni: udjel skeleta po genetskim horizontima, debljine horizonata i ukupna dubina profila. Na uzetim uzorcima iz genetskih horizonata u laboratorijima je određeno: granulometrijski sastav tla (HRN ISO 11277:2004), postojanost strukturnih mikroagregata prema Pernar et al. (2013) i mineralni sastav tla (XRD) metodom rendgenske difrakcije na rendgenskom difraktometru X'Pert PRO MPD.

Za potrebe statističke analize matični supstrat podijeljen je na šest karakterističnih cjelina, vodeći se većim dijelom podjelom koju su koristili Halamić et al. (2001) prilikom geokemijskih istraživanja potočnih sedimenata Medvednice. Litološku cjelinu LIT1 predstavljaju metamorfne stijene, dominantno zeleni škriljavci, muskovit-kloritski i kvarc-muskovitski škriljavci. Litološku cjelinu LIT2 predstavljaju metamorfne stijene, dominantno filiti. Litološka cjelina LIT3 su magmatske stijene, dominantno dijabazi i spiliti. Litološka cjelina LIT 4 su mezozojske klastične stijene donjokredske starosti, a obuhvaćaju pješčenjake, siltite i šejlove. Litološku cjelinu LIT5 predstavljaju mezozojske i tercijarne klastične stijene dominantno zastupljene laporima. LIT6 čine tercijarne karbonatne stijene predstavljene litotamnijskim vapnencima zajedno s glinovitim vapenencima (slika 1).

Statistička analiza napravljena je u programskom paketu Statistica 7. Za sve analizirane varijable napravljena je deskriptivna statistika: broj uzoraka, aritmetička sredina i standardna devijacija. Razlika između analiziranih varijabli po litološkim cjelinama testirane su jednostrukom analizom varijance (ANOVA) ako je zadovoljen uvjet homogenosti varijance. Za varijable kod kojih nije zadovoljen test homogenosti varijance korišten je Kruskal-Wallisov neparametrijski test. Greška tipa I ( $\alpha$ ) od $5 \%$ smatrana je statistički značajnom.

\section{REZULTATI ISTRAŽIVANJA I RASPRAVA RESEARCH RESULTS AND DISCUSSION}

$\mathrm{Na}$ otvorenim pedološkim profilima utvrđeni su sijedeći tipovi tala: distrični kambisol, eutrični kambisol, kalkokambisol, stagnosol, regosol i luvisol (postotni omjer po zastupljenosti iznosi $62 \%-19 \%-10 \%-4 \%-3 \%-2 \%)$. 
Tablica 1. Srednje vrijednosti (aritmetička sredina i standardna devijacija) istaživanih fizičkih i mineralnih značajki tala razvijenih na različitim litološkim cjelinama u humusnoakumulativnom (A-horizont) i B-horizontu

Table 1. Mean values (arithmetic mean and standard deviation) for the investigated physical and mineral properties of the soils developed in different lithological units in the humus-accumulative (A horizon) and B horizot

\begin{tabular}{|c|c|c|c|c|c|c|c|}
\hline & & & Matični supstra & Parent material & & & \\
\hline $\begin{array}{l}\text { Varijable } \\
\text { Variable }\end{array}$ & 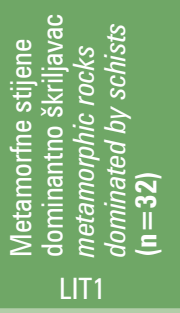 & 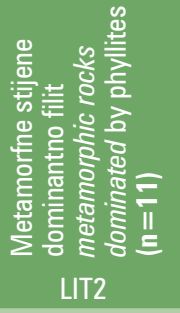 & 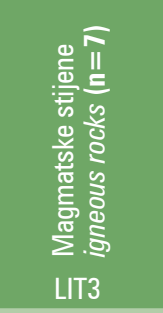 & 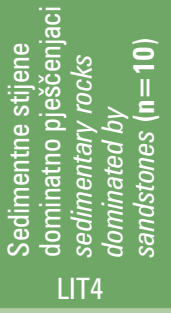 & 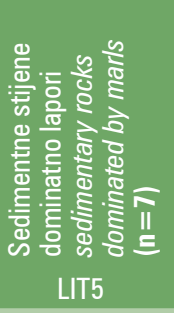 & 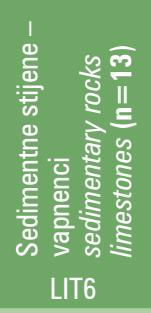 & 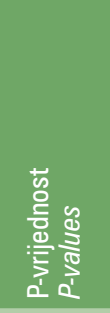 \\
\hline & & & A horizon & & & & \\
\hline $\begin{array}{l}\text { Debljina A - horizonta } \\
\text { thickness } A \text { - horizon }(\mathrm{cm})\end{array}$ & $6.0 \pm 4.8$ & $2.9 \pm 1.9$ & $7.1 \pm 3.2$ & $3.1 \pm 1.5$ & $4.2 \pm 3.5$ & $4.5 \pm 2.8$ & 0.0850 \\
\hline $\begin{array}{l}\text { Skelet } \\
\text { Skelet (\%) }\end{array}$ & $11.7 \pm 9.5$ & $8.5 \pm 13.0$ & $35.0 \pm 17.6$ & $4.8 \pm 5.8$ & $1.9 \pm 3.7$ & $0.2 \pm 0.6$ & $<0.0001$ \\
\hline $\begin{array}{l}\text { Krupni pijesak } \\
\text { Coarse sand (\%) }\end{array}$ & $16.6 \pm 6.5$ & $14.8 \pm 8.3$ & $15.6 \pm 2.2$ & $17.1 \pm 13.1$ & $1.7 \pm 1.3$ & $3.2 \pm 2.6$ & $<0.0001$ \\
\hline $\begin{array}{l}\text { Sitni pijesak } \\
\text { Fine sand }(\%)\end{array}$ & $8.0 \pm 3.5$ & $7.2 \pm 2.3$ & $5.5 \pm 2.3$ & $6.6 \pm 3.5$ & $5.6 \pm 2.2$ & $6.0 \pm 2.9$ & 0.1962 \\
\hline $\begin{array}{l}\text { Krupni prah } \\
\text { Coarse silt (\%) }\end{array}$ & $16.1 \pm 3.9$ & $18.7 \pm 5.9$ & $16.8 \pm 4.5$ & $18.0 \pm 8.5$ & $23.2 \pm 5.2$ & $19.7 \pm 5.4$ & 0.0389 \\
\hline $\begin{array}{l}\text { Sitni prah } \\
\text { Fine silt (\%) }\end{array}$ & $34.4 \pm 5.9$ & $35.3 \pm 4.9$ & $36.7 \pm 7.4$ & $34.7 \pm 5.9$ & $41.9 \pm 4.7$ & $33.4 \pm 4.3$ & 0.0201 \\
\hline $\begin{array}{l}\text { Glina } \\
\text { Clay (\%) }\end{array}$ & $24.8 \pm 5.8$ & $24.0 \pm 2.3$ & $25.4 \pm 6.4$ & $23.7 \pm 4.6$ & $27.6 \pm 7.1$ & $37.6 \pm 4.8$ & $<0.0001$ \\
\hline $\begin{array}{l}\text { Kvarc } \\
\text { Ouartz (\%) }\end{array}$ & $9.2 \pm 5.6$ & $12.9 \pm 5.0$ & $7.4 \pm 3.0$ & $21.3 \pm 4.5$ & $17.6 \pm 5.9$ & $18.1 \pm 3.2$ & $<0.0001$ \\
\hline $\begin{array}{l}\text { Muscovit/ilit } \\
\text { Muscovite/illite (\%) }\end{array}$ & $29.1 \pm 6.3$ & $29.3 \pm 7.3$ & $27.6 \pm 2.8$ & $27.6 \pm 2.8$ & $30.2 \pm 3.9$ & $29.5 \pm 1.7$ & 0.9130 \\
\hline $\begin{array}{l}\text { Klorit } \\
\text { Chlorite (\%) }\end{array}$ & $22.7 \pm 3.6$ & $21.5 \pm 4.1$ & $26.3 \pm 2.1$ & $19.1 \pm 2.3$ & $20.7 \pm 2.4$ & $21.2 \pm 2.4$ & 0.0020 \\
\hline $\begin{array}{l}\text { Feldspata } \\
\text { Feldspar }(\%)\end{array}$ & $32.3 \pm 4.0$ & $30.0 \pm 5.4$ & $37.6 \pm 2.8$ & $29.6 \pm 2.1$ & $29.9 \pm 1.9$ & $30.8 \pm 1.8$ & 0.0013 \\
\hline $\begin{array}{l}\text { Stabilnost mikroagregata } \\
\text { Microaggregate stability (\%) }\end{array}$ & $96.4 \pm 1.4$ & $95.7 \pm 2.5$ & $97.5 \pm 1.8$ & $96.0 \pm 1.8$ & $94.8 \pm 2.5$ & $95.6 \pm 3.5$ & 0.3781 \\
\hline & & & B horizon & & & & \\
\hline $\begin{array}{l}\text { Dubina profila } \\
\text { Profile depth }(\mathrm{cm})\end{array}$ & $70.7 \pm 30.5$ & $87.1 \pm 21.1$ & $80.7 \pm 36.8$ & $91.2 \pm 21.6$ & $110.7 \pm 36.3$ & $50.7 \pm 20.6$ & 0.0179 \\
\hline $\begin{array}{l}\text { Debljina B - horizonta } \\
\text { thickness } B \text { - horizon (cm) }\end{array}$ & $35.2 \pm 17.5$ & $40.4 \pm 16.8$ & $51.9 \pm 20.4$ & $35.2 \pm 10.7$ & $39.7 \pm 17.0$ & $34.3 \pm 15.6$ & 0.2012 \\
\hline $\begin{array}{l}\text { Skelet } \\
\text { Skelet }(\%)\end{array}$ & $23.7 \pm 15.6$ & $8.8 \pm 8.1$ & $61.4 \pm 22.3$ & $23.3 \pm 18.9$ & $3.3 \pm 4.7$ & $1.4 \pm 3.0$ & $<0.0001$ \\
\hline $\begin{array}{l}\text { Krupni pijesak } \\
\text { Coarse sand }(\%)\end{array}$ & $17.8 \pm 7.7$ & $16.0 \pm 8.2$ & $16.7 \pm 5.4$ & $13.2 \pm 8.4$ & $1.8 \pm 1.4$ & $3.6 \pm 3.9$ & $<0.0001$ \\
\hline $\begin{array}{l}\text { Sitni pijesak } \\
\text { Fine sand (\%) }\end{array}$ & $8.5 \pm 3.2$ & $8.1 \pm 2.8$ & $6.4 \pm 2.2$ & $7.1 \pm 3.3$ & $5.3 \pm 2.3$ & $7.5 \pm 5.4$ & 0.2368 \\
\hline $\begin{array}{l}\text { Krupni prah } \\
\text { Coarse silt (\%) }\end{array}$ & $16.6 \pm 5.2$ & $18.9 \pm 6.4$ & $17.4 \pm 5.1$ & $19.6 \pm 8.3$ & $22.0 \pm 5.1$ & $18.4 \pm 5.8$ & 0.2383 \\
\hline $\begin{array}{l}\text { Sitni prah } \\
\text { Fine silt (\%) }\end{array}$ & $36.2 \pm 7.4$ & $35.0 \pm 4.2$ & $36.2 \pm 5.0$ & $35.5 \pm 6.6$ & $42.4 \pm 4.8$ & $29.6 \pm 7.5$ & 0.0022 \\
\hline $\begin{array}{l}\text { Glina } \\
\text { Clay }(\%)\end{array}$ & $20.9 \pm 7.0$ & $22.0 \pm 4.9$ & $23.2 \pm 3.6$ & $24.6 \pm 2.8$ & $28.5 \pm 7.6$ & $40.8 \pm 5.6$ & $<0.0001$ \\
\hline $\begin{array}{l}\text { Kvarc } \\
\text { Quartz (\%) }\end{array}$ & $10.1 \pm 5.4$ & $14.3 \pm 6.4$ & $8.0 \pm 3.6$ & $19.6 \pm 5.4$ & $20.4 \pm 7.4$ & $17.5 \pm 5.0$ & $<0.0001$ \\
\hline $\begin{array}{l}\text { Muscovit/ilit } \\
\text { Muscovite/illite (\%) }\end{array}$ & $28.9 \pm 6.4$ & $31.3 \pm 6.3$ & $28.0 \pm 2.8$ & $30.5 \pm 4.1$ & $32.1 \pm 4.9$ & $29.4 \pm 3.0$ & 0.4792 \\
\hline $\begin{array}{l}\text { Klorit } \\
\text { Chlorite (\%) }\end{array}$ & $22.8 \pm 3.45$ & $21.1 \pm 3.2$ & $25.6 \pm 2.6$ & $19.4 \pm 2.4$ & $18.3 \pm 1.4$ & $21.9 \pm 1.5$ & $<0.0001$ \\
\hline $\begin{array}{l}\text { Feldspata } \\
\text { Feldspar (\%) }\end{array}$ & $31.6 \pm 4.1$ & $28.4 \pm 2.5$ & $36.7 \pm 3.2$ & $28.3 \pm 2.6$ & $27.7 \pm 2.2$ & $31.0 \pm 2.0$ & $<0.0001$ \\
\hline $\begin{array}{l}\text { Stabilnost mikroagregata } \\
\text { Microaggregate stability (\%) }\end{array}$ & $94.1 \pm 3.4$ & $92.3 \pm 3.7$ & $97.5 \pm 1.2$ & $93.2 \pm 4.4$ & $85.9 \pm 10.3$ & $95.9 \pm 2.3$ & 0.0001 \\
\hline
\end{tabular}



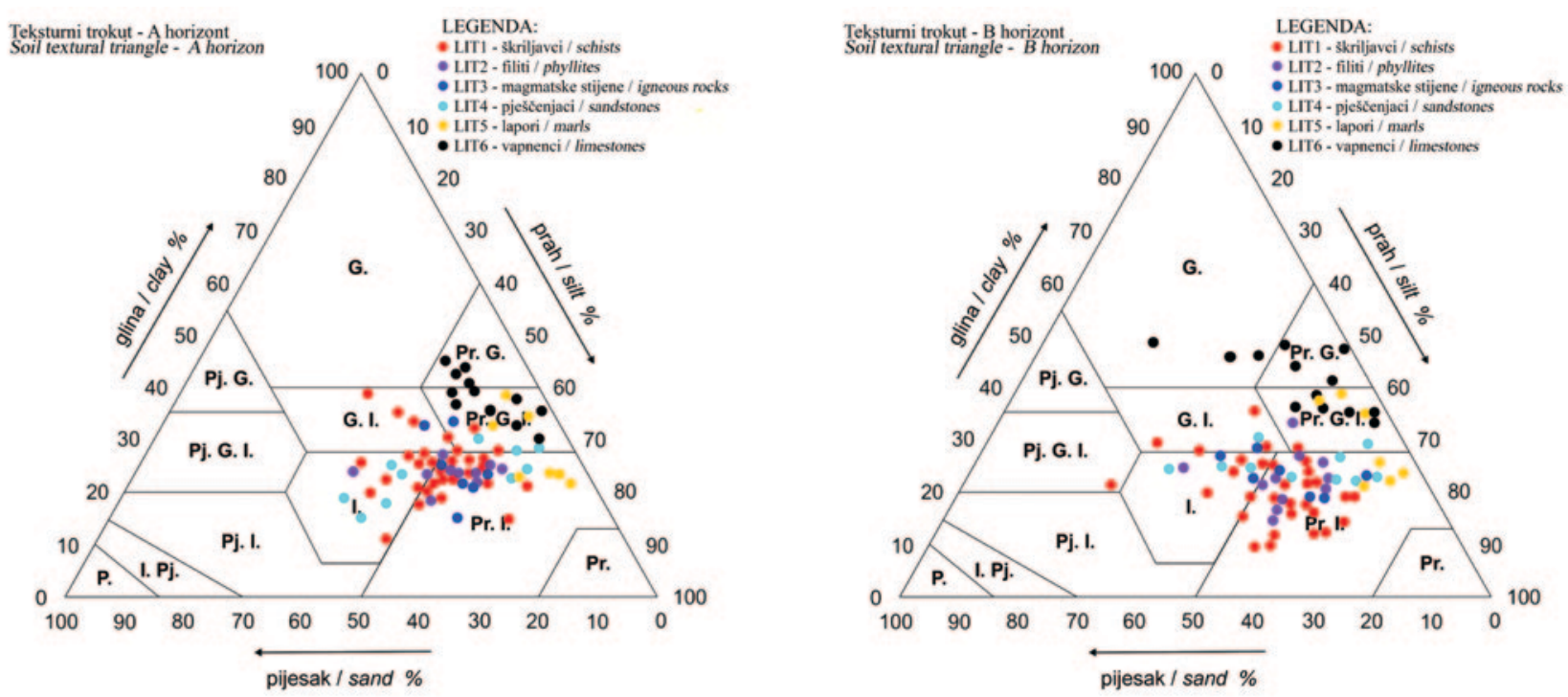

Slika 2. Teksturni trokut za A- i B-horizont po litološkim cjelinama (P. - pijesak; I. Pj. - ilovasta pijeskulja; Pj. I. - pijeskovita ilovača; Pj. G. I. pijeskovita glinasta ilovača; Pj. G. - pijeskovita glinuša; G. - glinuša; G. I. - glinasta ilovača; I. - ilovača; Pr. I. - praškasta ilovača; Pr. - prah; Pr. G. I. - praškasto glinasta ilovača; Pr. G. - praškasta glinuša).

Figure 2. Soil textural triangle for the A- and B-horizon per lithological unit (P. - sand; I. Pj. - loamy sand; Pj. I. - sandy loam; Pj. G. I. - sandy clay loam; Pj. G. - sandy clay; G. - clay; G. I. - clay loam; I. - loam; Pr. I. - silty loam; Pr. - silt; Pr. G. I. - silty clay loam; Pr. G. - silty clay).

Debljina humusnoakumulativnog horizonta na različitim litološkim cjelinama kreće se u rasponu od $3.1 \mathrm{~cm}$ na LIT4 do $7.1 \mathrm{~cm}$ na LIT3 bez statistički značajne razlike, što je uvjetovano ponajprijo velikom varijabilnošću debljine Ahorizonta (Pernar et al. 2009; Lin et al. 2005). Debljina Bhorizonta je od $34.3 \mathrm{~cm}$ na LIT6 do $51.9 \mathrm{~cm}$ na LIT3. Najveća prosječna vrijednosti ukupne dubine profila je 110.7 $\mathrm{cm}$. povrh LIT5 i ona se statistički značajno razlikuje $(\mathrm{F}=$ 2.9481; $\mathrm{p}=0.0179)$ od LIT6 $\mathrm{s}$ najmanjom dubinom profila $50.7 \mathrm{~cm}$. Na ostalim litološkim cjelinama prosječna dubina profila iznosi od 70.7 do $91.2 \mathrm{~cm}$ (tablica 1). Prema Martinoviću (2003) prosječne dubine profila na distričnim i eutričnim kambisolima kreću se u rasponu od 60 do $80 \mathrm{~cm}$, što je u skladu s dubinama na LIT1, LIT2, LIT3 i LIT4, gdje je distrični kambisol dominantan tip tla.

Prema udjelu pojedinih teksturnih frakcija nije utvrđena razlika po litološkim cjelinama između A- i B-horizonta, zbog čega su u radu prikazane međusobni odnosi po litološkim cjelinama za B-horizont. LIT5 i LIT6 imaju statistički značajno manji udjel frakcije krupnog pijeska $(\mathrm{H}(5, \mathrm{n}=80)$ = 40.49768; P < 0001) od LIT1, LIT2, LIT3 i LIT4. Litološke cjeline nisu se statistički značajno razlikovale $(\mathrm{F}=1.3974 ; \mathrm{P}$ $=0.2368$ ) prema udjelu sitnog pijeska. Udjeli frakcije sitnog pijeska kreću se u rasponu od $5.3 \%$ na LIT3 do $8.5 \%$ na LIT1. Udjel frakcije krupnog praha najveći je na LIT5 (22 $\%)$ bez statistički značajne razlike u odnosu na ostale litološke cjeline gdje se udjel kreće u rasponu od $16.6 \%$ do 19.6 $\%$. Najveći udjel frakcije sitnog praha (42.4\%) izmjeren je na LIT5, a najmanji (29.6\%) na LIT6. LIT5 s najvećim udjelom sitnog praha statistički se značajno razlikuje od LIT1 i LIT6 ( $\mathrm{F}=4.203 ; \mathrm{P}=0.0022)$. Na ostalim litološkim cjeli- nama udjel sitnog praha kreće se u rasponu od $35.1 \%$ (LIT2) do $36.2 \%$ (LIT3). S obzirom na udjel gline jasno se izdvaja LIT6 s najvećima udjelom (40.8 \%), koja se statistički značajno razlikuje od svih ostalih litoloških cjelina ( $\mathrm{F}=17,738$; $\mathrm{P}<0.0001)$. Ovi rezultati za udjel gline slažu se s podacima za tla povrh vapnenačkih podloga na području Turske (Gökbulak \& Özcan, 2008). Veće udjele gline na vapnenačkoj podlozi na području Medvednici utvrdio je Vrbek (2009). Na ostalim litološkim cjelinama udjel gline kreće se u rasponu od $20.9 \%$ (LIT1) do $28.5 \%$ (LIT5) (tablica 1). Galović (2014) je na Medvednici utvrdila da tla povrh silikatne litološke podloge imaju prosječno grublji granulometrijski sastav od tala povrh karbonatnih matičnih supstrata, što je u skladu s rezultatima u ovom istraživanju. Teksturne oznake tala na LIT1, LIT2, LIT3 i LIT4 kreću se u rasponu od praškaste ilovače do glinaste ilovače, na LIT5 od praškaste ilovače do praškasto glinaste ilovače, dok je jasno izdvojena LIT6 s dominantnom teksturnom oznakom praškasta glinuša do glinuša u B-horizontu (slika 2). Martinović (2003) navodi da kalkokambisol koje je najzastupljenije tlo povrh LIT6 ima teksturnu oznaku od glinovite ilovače do gline. Pritom treba istaknuti da je većina profila na Medvednici skeletoidnog karaktera (Pernar et al. 2013). Neki imaju veći sadržaj skeleta već od same površine, ili je površinski horizont i sama površina tla obogaćena prenesenim detritusom. Prema udjelu skeleta u B-horizontu jasno su se izdvojile tri grupe litoloških cjelina koju čine LIT3 s najvećim udjelom skeleta (61 \%), LIT4, LIT5 i LIT6 (2 do 3 \%) s najmanjim udjelom skeleta, dok se LIT1 i LIT2 (9 do $24 \%$ ) nalaze između gore navedenih grupa. LIT3 se statistički značajno razlikuje od LIT4, LIT5 i LIT6, dok se LIT1 statistički zna- 


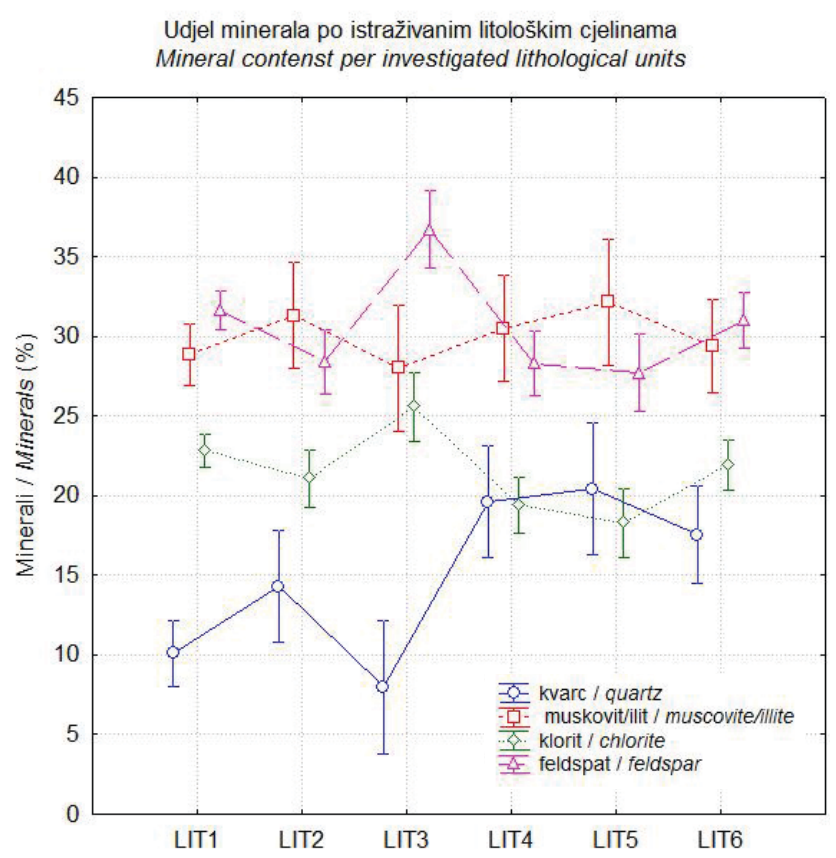

Slika 3. Udjel minerala po istraživanim litološkim cjelinama u B-horizontu

Figure 3. Mineral contents per investigated lithological units in B horizont

čajno razlikuje od LIT6 $(\mathrm{H}(5, \mathrm{n}=76)=40.3700 ; \mathrm{P}<0.0001)$. $\mathrm{S}$ porastom dubine raste i udjeli skeleta na svim litološkim cjelinama, s tim da to do posebnog izražaja dolazi na LIT 4 (A-horizont - $5 \%$; B-horizont - 23\%) i LIT3 (A-horizont 35\%; B-horizont - 61\%) (tablica 1).

Prema indeksu postojanosti mikroagregata na svim litološkim cjelinama tlo je vrlo postojanih mikroagregata. Postojanost strukturnih mikroagregata u B-horizontu je niža u odnosu na humusnoakumulativni horizont (tablica 1). Na, u pravilu, veću postojanost mikroagregata u površinskom horizontu upućuju i istraživanja (Zhanga et al., 1996; Wei et al., 2006), koji navode da je njihova veća postojanost u površinskom horizontu uzrokovana većim udjelom organske tvari. Visoke vrijednosti postojanoti mikroagregata u ovom istraživanju su u skladu s rezultatima koje je dobio Caravaca et al. (2004) proučavajući indeks postojanosti agregata u šumskoj sastojini u odnosu na poljoprivrednu površinu. Stabilnost agregata predstavljaju jedan od ključnih indikatora za kvalitetu i stanje tla (Herrick et al., 2001; Neal et al., 2004.) i otpornosti na eroziju (Barthes \& Rosse, 2002; Ramos et al., 2003). Na temelju gore navedenih literaturnih izvora tla na Medvednici spadaju, s obzirom na mogućnost pojave erozije, u stabilna tla. Razlog tome leži i u činjenici da su svi profili otvoreni pod šumskom sastojinom koja predstavlja djelotvornu zaštitu od erozije (Butorac 2011; Vrbek 2009).

Rezultati semikvantitativne mineralne analize pokazali su da prema udjelu analiziranih minerala između litoloških cjelina na istraživanom području postoje značajne razlike (slika 3). S obzirom na udjel kvarca $(\mathrm{n}=77)$ izdvajaju se dvije grupe litoloških cjelina: LIT1, LIT2 i LIT3 s manjim udjelima u odnosu na LIT4, LIT5 i LIT 6. LIT4 se statistički značajno razlikuje od LIT1, LIT2 i LIT3, dok se LIT5 i LIT6 statistički značajno razlikuju od LIT1 i LIT3 ( F = 11.747; P $<0001$ ). Najveći udjel kvarca je na LIT5, iznosi $20.4 \%$, dok je najmanji na LIT3 i iznosi $8.0 \%$ (slika 3). Kvarc je jedan od posljednjih minerala koji se kristalizira iz magme, zbog čega je izrazito otporan na trošenje (Bowen, 1956). Veći udjel kvarca na pješčenjacima objašnjava se njegovom otpornošću na trošenje uslijed transformacije metamorfnih i magmatskih stijena (Allen \& Hajek, 1989). Ehlers \& Blatt (1982) daju prosječne vrijednosti za kvarc u magmatskim stijenama u iznosu od $200 \mathrm{~g} \mathrm{~kg}^{-1}$ s $\mathrm{s}$ tim da navode da su veće vrijednosti u magmatskim stijenama bogatim silikatima u odnosu na bazične magmatske stijene od kojeg je građena Medvednica (Šikić, 1995). Scheffer i Schachtachbel (1998) navode udjel kvarca od $12 \%$ u magmatskim stijenama, što je nešto veća vrijednost u odnosu na rezultate na Medvednici. Udjeli muskovit/ilita na svim istraživanim litološkim cjelinama nisu se statistički značajno razlikovali (slika 3). Najmanji udjel muskovit/ilita je na LIT3 (28.0 \%), dok je najveći na LIT5 (32.1 \%). Na homogenim matičnim supstratima udjel tinjaca u pravilu raste s povećanjm dubine (Schumacher \& Perkins, 1987) - to se pokazalo i u ovom istraživanju s izuzetkom LIT1 (tablica 1). Prema Fanning et al. (1989) muskovit i biotit su najznačajniji minerali tinjaca u metamorfnim i magmatskim stijenama, dok Johnson (1970) navodi da je ilitni tinjac najdominantniji mineral gline u tlima povrh šejlova i vapnenaca. Aritmetička sredina udjela klorita $(\mathrm{N}=77)$ je u rasponu od $18.3 \%$ povrh LIT5 do $25.6 \%$ povrh LIT3. LIT3 s većim udjelom klorita statistički značajno se razlikuje od LIT2, LIT4, LIT5 i LIT6, dok se LIT1 statistički značajno razlikuje od LIT4 i LIT5 (F $=7.463 ; \mathrm{P}<0.0001)$. U literaturi postoji opće prihvaćeno mišljenje da je klorit u tlu naslijeđen od matičnog substrat, i da je nestabilan uslijed pedogenetskih procesa. Kao rezultat tih svojstava, klorit se najčešće pojavljuje na relativno nepromijenjenim matičnim supstratima (Allen \& Hajek, 1989). Srednje vrijednosti udjela feldspata između litoloških cjelina pokazuju slične odnose kao i kod udjela klorita. Prema udjelu feldspata jasno je izdvojena LIT3 s najvećim udjelom u odnosu na ostale litološke cijeline. Udjel fedspata na LIT3 iznosi $36.7 \%$ i statistički se značajno razlikuje (H $(5, \mathrm{n}=76)=26.5901 ; \mathrm{P}<0001)$ od LIT2, LIT4 i LIT5. Prema Clarke i Jeffriesu (po Scheffer - Schachtachbel, 1998) udjel feldspata u magmatskim stijenama može iznositi i do $60 \%$, na šejlovima $30 \%$ i na pješčenjacima $11.5 \%$. Na ostalim litološkim cjelinama udjel fedspata kreće se u rasponu od 27.7 \% povrh LIT5 do $31.6 \%$ povrh LIT1 (slika 3 ).

U kontekstu ovih istraživanja pokazala se sva kompleksnost i heterogenost geološko-litološke građe Medvednice. Ona se ovdje u konstelaciji i ostalih pedogenetskih čimbenika reflektira u još većoj heterogenosti tla, što u konačnici stvara teškoće prilikom obrade i interpretacije rezultata. 
Ovim istraživanjem dobiveni su referentni podaci o fizičkim i mineralnim značajkama tla na području PP Medvednica na najzastupljenijim litološkim cjelinama, koje međutim treba s oprezom uzeti uspoređujući ih s rezultatima drugih sličnih studija, jer se na istoj litološkoj podlozi mogu formirati tla različite taksonomske pripadnosti, ovisno o promjenama konstelacije ostalih pedogenetskih čimbenika (klima, vegetacija i reljef).

\section{ZAKLJUČCI}

\section{CONCLUSIONS}

Na temelju usporedbe tala formirnih na šest različitih litoloških cjelina može se utvrditi:

1. Praškasta do glinasta ilovača je najzastupljenija teksturna klasa na području PP Medvednice, a utvrđena je na metamorfnim stijenama povrh zelenog škriljavca i filita, magmatskih stijena, pješčenjaka i lapora, dok je na lako trošivim vapnencima teksturna klasa od praškaste glinuše do glinuše. Iz analize granulometrijskog sastava tla (udjela pojedinih frakcija) utvrđeno je da profili razvijeni na silikatnim litološkim podlogama imaju prosječno veći udjel pijeska od profila razvijenih na karbonatnim stijenama, što je uzrokovano načinom trošenja matične stijene. Veći udjel gline povrh lako trošivih vapnenaca na kraju je utjecao i na različitost teksturne klase u odnosu na ostale litološke cjeline.

2. Na svim istraživanim litološkim cjelinama prema postojanosti strukturnih mikroagregata. Tla na području PP Medvednice vrlo su postojanih mikroagregata. U odnosu na B-horizont, $\mathrm{u}$ humusnoakumulativnom horizontu utvrđena je veća postojanost strukturnih mikroagregata, što se može povezati s većim udjelom organske tvari u površinskom horizontu.

3. Tla povrh magmatskih i metamorfnih stijena imaju značajno manji udjel minerala kvarca i veći udjel minerala klorita i feldspata u odnosu na tlo povrh sedimentnih stijena. Udjeli muskovit/ilita nisu se razlikovali između litoloških podloga.

4. Najveće dubine tla su povrh laporovitih stijena, a najmanje na dolomitiziranim vapnencima, što je ponajprije uvjetovano načinom trošenja matičnog supstrata.

\section{LITERATURA}

\section{REFERENCES}

- Allen, B. L, B. F. Hajek,1989: Mineral occurrence in soil environments.In: JB Dixon and SB Weed (Editors). Minerals in Soil Environments. 2nd Ed. Soil Sci. Soc.Am.. Madison. WI. pp. 199278.

- Badia, D., C. Marti, J. M. Aznar, J. Leon, 2013: Influence of slope and parent rock on soil genesis and classification in semiarid- mountainous environments. Geoderma 193-194 (2013). pp. $13-21$.

- Bakšić, D., N. Pernar, I. Perković, B. Vrbek, V. Roje, 2015: Raspodjela zemnoalkalijskih i alkalijskih kovina (Ca. Mg. K. $\mathrm{Na}$ ) u šumskom tlu Parka prirode Medvednica. Šumarski list.

- Barthès, B., E. Roose, 2002: Aggregate stability as an indicatorof soil susceptibility to runoff and erosion: Validation at severallevels. Catena, 47(2), 133-149.

- Basch, O., 1983a: Osnovna geološka karta SFRJ, List Ivanić Grad 1:100000, L 33-81. Geološki zavod, Zagreb (1980), Savezni geološki zavod Beograd.

- Basch, O., 1983b: Osnovna geološka karta SFRJ 1:100000 Tumač za List Ivanić Grad, L 33-81. Geološki zavod, Zagreb (1980), Savezni geološki zavod, Beograd.

- Birkeland, P. W., 1999: Soil and Geomorphology.Oxford University press. New York. pp. 430.

- Bockheim, J. G., A. N. Gennadiyev, R. D. Hammer, J. P. Tandarich, J. P. 2005. Historical development of key concepts in pedology. Geoderma 124. 23-36.

- Boewen, N. L., 1956: The evolution of the igneous rocks. Dover Publ. New York, NY.

- Brady, N. C., 1990: The Nature and Properties of Soil. Tenth ed. Macmillan. New York.

- Brewer, R., 1954. Soil Partent Material. The Australian Journal of Sciences 16. Pp. 134-138.

- Burke, A., 2002. Properties of soil pockets on arid Nama Karoo inselbergs-the effect of geology and derived landforms. Journal of Arid Environments 50.pp. 219-234.

- Butorac, L., 2011: Uloga i značaj šumske vegetacije na kršu u zaštiti tla od erozije. Zagreb. Doktorska disertacija, str. 1 - 149.

- Carvavaca, F., A. Lax, J. Albaladejo, 2004: Aggregate stability and carbon characteristics of particle-size fractions in cultivated and forested soils of semiarid Spain. Soil and Tillage Research 78 (2004). pp. 83-90.

- Coffey, G. N., 1912. A Study of the Soils of the United States. USDA Bur. of Soils Bull.. vol. 85. U.S. Govt. Print. Office. Washington. DC.

- Dokuchaev, V. V., 1883. The Russian Chernozem Report to the Free Economic Society (in Russian). Imperial Univ. of St. Petersburg. St. Petersburg. Russia.

- Ehlers, E. G., H. Blatt, 1982: Petrology : igneous, sedimentary, and metamorphic / New York: Freeman, pp. 732.

- Fanning D. S., V. Z. Keramidas, M. A. El-Desoky, 1989: Micas. In: JB Dixon and SB Weed (Editors). Minerals in Soil Environments. 2nd Ed. Soil Sci. Soc. Am.. Madison. WI. pp. 551-634.

- FAO (2006). Guidelines for soil description, fourth ed. FAO, Rome

- Galović L., Z. Peh, 2014: Eolian contribution to geochemical and mineralogical characteristics of some soil types in Medvednica Mountain, Croatia. Catena 117 (2014), pp. 145-156.

- Gökbulak, F., M. Özcan, 2008: Hydro-physical properties of soils developed from different parent materials. Geoderma 145 (2008). pp. 376-380.

- Halamić, J., Z. Peh, D. Bukovec, S. Miko, L. Galović, 2001: A Factor Model of the Relationship between Stream Sediment Geochemistry and Adjacent Drainage Basin Lithology. Medvednica Mt.. Croatia. Geologia Croatica. 54/1. Croatian Geological Survey Zagreb.pp. 37-51. 
- Herrick, J. E., W. G. Whitford, A. G. de Soyza, J. W. van Zee, K. M. Havstad, C. A. Seybold, M. Walton, 2001: Field soilaggregate stability kit for soil quality and rangeland healthevaluations. Catena, 44(1), 27-35.

- Hilgard, E. W., 1906. Soils: Their Formation. Properties. Composition. and Relations to Climate and Plant Growth in the $\mathrm{Hu}$ mid and Arid Regions. Macmillan. NY.

- HRN ISO 11277, 2011: Kvaliteta tla - Određivanje raspodjele veličine čestica (mehaničkog sastava) u mineralnom dijelu tla - Metoda prosijavanja i sedimentacije (u skladu s ISO 11277:2009). Hrvatski zavod za normizaciju. Zagreb.

- HRN ISO 11464, (2004): Kakvoća tla - Pripremanje uzoraka za fizikalne i kemijske analize(u skladu s ISO 11464:1994). Hrvatski zavod za normizaciju. Zagreb.

- Jenny, H., 1994: Factors of soil formation: a system of quantitative pedology. Dover Publivations. Inc. NY (first published by the McGraw-Hill Book Company. Inc. 1941). pp. 1-191.

- Johnson, L. J., 1970: Clay minerals in Pennsylvania soils. Relation to litology of the parent rock and other factors. Clays Clay Miner. 18:828-838.

- Kooijman, A. M., J. Jongejans, J. Sevink, 2005: Parent material effects on Mediterranean woodland ecosystem in NE Spain. Catena 59. pp. 55-68.

- Lin, H. S., D. Wheeler, J. Bell, L. Wilding, 2005: Assessment of soil spatial variability at multiple scales. Ecological Modelling 182. pp. 271-290.

- Martinović, J., A. Vranković, 1997: Baza podataka o hrvatskim tlima. sv. I. DUZO. str. 1-364. Zagreb.

- Martinović, J., 2003: Gospodarenje šumskim tlima u Hrvatskoj. Jastrebarsko. pp. 1-525

- Nael, M., H. Khademi, M. A. Hajabbasi, 2004: Response of soilquality indicators and theirspatial variability to land degradation in central Iran. Appl. Soil Ecol., 27(3), 221-232.

- Olatunji, O. O. M., A. O. Ogunkunle, F. O. Tabi, F. O. 2007: Influence of Parent Material and Topography on some Soil Properties inSouthwestern Nigeria. Nig. J. Soil \& Env. Res. Vol. 7: 2007. pp. 1-6.
- Olowolafe, E. A., 2002: Soil parent materials and soil properties in two separatecatchment areas on the Jos Plateau Nigeria. GeoJournal 56. pp. 201-212.

- Osher, L. J., S. W. Buol, 1998: Relationship of soil properties to parent material and landscape position in eastern Madre de Dios. Geoderma 83. pp. 143-166.

- Pamić, J., J. Injuk, 1986: Petrološko-geokemijske karakteristike ortogrinšista Zagrebačke gore u Hrvatskoj. Geologija 28. 29. Ljubljana. pp. 239-254.

- Pernar, N., D. Bakšić, I. Perković, 2013: Terenska i labaratorijska istrațivanja tla - priruĉnik za uzorkovanje i analizu. Zagreb 2013. str. 1-191.

- Pernar, N., J. Vukelić, D. Bakšić, D. Baričević, I. Perković, S. Miko, B. Vrbek, 2009: Soil properties in beech-fire forests on Mt. Medvednica (NW Croatia) Periodicum bilogorum 57:61. VOL. 111. No 4. pp. 427-434.

- Ramos, M. C., S. Nacci, I. Pla, 2003:. Effect of raindrop impactand its relationship with aggregate stability to different disaggregation forces. Catena, 53(4), 365-376.

- Scheffer, F., P. Schachtschabel, 1998: Lehrbuch der Bodenkunde. Ferdinand Enke Verlag Stuttgart.

- Schumacher, B. R., H. F. Perkins, 1987: Soil genesis in a development sequence of soil formed in sillimanite mica schist residuum. Soil. Sci. Soc. Am. J. 51: 1238 - 1242.

- Šikić, K., 1995: Geološki vodič Medvednice. Institut za geološka istraživanja. Zagreb. INA-Industrija nafte d.d. Naftaplin Zagreb. pp. 199

- Vrbek, B., 2009: Istraživanje tipova tala područja J. U. „Park prirode Medvednica“ s izradom karte karte tala mjerila 1:25000. Hrvatski šumarski institut. Jastrebarsko 2009. str. 1-58.

- Vranković, A., 1973: Tla na kalcitnim i nekim silikatnim metamorfitima metamorfnog facijesa zelenog škriljca u Zagrebačkoj gori i Papuku. Magistarski rad.

- Zhang, M. K., Z. E. He, G. C. Chen, C. Y. Huang, M. J. Wilson, M. J. 1996: Formation and water stability of aggregates in red soils as affected by organic matter. Pedosphere. 6(1). pp. 39-45.

- Wei, C., M. Gao, J. Shao, D. Xei, G. Pan, 2006: Soil aggregate and its response to land management practices. China particuology Vol. 4. No. 5. pp. 211-219.

\section{Sažetak - Summary}

The highly complex lithological structure as well as topographic characteristics of the Medvednica area are responsible for its profound vegetational, micro-climatic and pedophysiographic diversity. In view of the quality of the original soil-forming material, the first place is taken by rocks and their detritus which directly govern soil physical composition. The best indicators of soil physical composition are its depth, colour, skeletal nature, particle size distribution, soil density, density of soil solid phase, total porosity, water capacity, air capacity, structure and hydraulic properties. On Medvednica, these vary greatly and play the main role in defining soil quality. The success of ecosystem management depends on the knowledge of the above factors. The goal of this research is to determine how the lithological base, or parent material, primarily affects physical (horizon thickness, profile depth, skelet proportion, soil texture, soil structure) and mineral soil properties.

A total of 80 pedological profiles were opened in the Medvednica Nature Park area and evenly distributed so as to comprise all the representative lithological units. Samples of physically altered soils were taken from genetic horizons, as well as a fragment of rock, i.e. parent material, for the purpose of determining the lithological rock affiliation. Soil samples has been analayzed in the humus-accumulative (A horizon) and first under mineral horizon (mostly B horizon). The differences between the topsoil humus-accumulative and B horizon were statistically analyzed per lithological units. The samples were prepared (ISO 11464 2006) and analyzed in the laboratories of the Faculty of Forestry of the University of Zagreb and at the Croatian Geo- 
logical Institute in Zagreb. According to FAO (2006), the following was determined in situ: the proportion of skelet per genetic horizon, horizon thicknesses and total profile depth. Laboratory analyses of the samples taken from genetic horizons included the particle size distribution according to ISO 11277:2009, stability of structural microaggregates according to Pernar et al. (2013) and mineral soil composition (XRD) using the X-ray diffraction method on X-ray diffractrometer X'Pert PRO MPD.

For the needs of statistical analysis, parent material was divided into six characteristic units, leaning in part on the classification of Halamić et al. (2001) used during geochemical research of stream sediments on Medvednica. The lithological unit LIT1 is represented by metamorphic rocks, predominantly greenschists, muscovite chlorite and quartz-muscovite schists. The lithological unit LIT2 is represented by metamorphic rocks, predominantly phyllites. The lithological unit LIT3 consists of igneous rocks, predominantly diabases and spilites. The lithological unit LIT4 are Mesozoic clastic rocks of Lower Cretaceous age, and comprise sandstones, siltites and shales. The lithological unit LIT5 consists of Mesozoic and Tertiary clastic rocks dominantly represented by marls. LIT6 is made up of Tertiary carbonate rocks represented by lithotamnic limestones together with clay limestones (Figure 1).

Statistical analysis was performed with Statistica 7 software. Descriptive statistics was made for all the analyzed variables, including the number of samples, arithmetic means and standard deviation. Differences between the analyzed variables by lithological units were tested with a one-way analysis of variance (ANOVA), on condition that the assumption of homogeneity of variance was satisfied. For those variables in which the test of homogeneity of variance was not satisfied, the Kruskal-Wallis non-parametric test was used. Type I error (a) of $5 \%$ was considered statistically significant.

The following soil types were identified in the opened pedological profiles: dystric cambisol, eutric cambisol, calcaric cambisol, stagnosol, regosol and luvisol (the percentage ratio by representation is $62 \%-19 \%-10$ $\%-4 \%-3 \%-2 \%)$.

Based on the comparison of soils formed in six different lithological units, it can be concluded that physical and mineral soil properties depending on type of litological units. Silty to clay loam is the most represented textural class in Medvednica Nature Park. It was found on metamorphic rocks above greenschist and phyllite, igneous rocks, sandstones and marls, whereas on easily weathered limestones the textural class ranges from silty clay to clay. The analysis of particle size distribution (content of individual fractions) showed that the profiles developed on silicate lithological parent material have on average higher sand content compared to the profiles developed on carbonate rocks, which is conditioned by the manner of parent rock weathering. Higher clay content above easily weathered limestones eventually led to variability of the textural class in relation to other lithological units. In all the investigated lithological units in terms of structural microaggregate stability, the soils in Medvednica Nature Park manifest highly stable microaggregates. In relation to the Bhorizon, the humus-accumulative horizon revealed higher stability of structural microaggregates, which can be attributed to higher content of organic matter in the topsoil horizon. The soils above igneous and metamorphic rocks have significantly lower content of the mineral quartz and higher content of the minerals chlorite and feldspar in relation to the soil above sedimentary rocks. There was no difference in muscovite/illite contents in lithological substrates. Soil was the deepest above marl rocks and the shallowest above dolomitised limestones, which is primarily conditioned by the manner of parent material weathering.

Our research highlights all the complexity and heterogeneity of the geological-lithological structure of Medvednica. In combination with other pedogenetic factors, it manifests even higher soil heterogeneity, which eventually causes problems in the processing and interpretation of the results.

This research provides reference data on physical and mineral properties of soils in Medvednica Nature Park in the most represented lithological units. However, these data should be taken with caution and should be compared with the results of other similar studies, since the same lithological parent material may give rise to the formation of soils of different taxonomic affiliation, depending on the changes in the constellation of other pedogenetic factors (climate, vegetation, relief).

KEY WORDS: parent material, lithological unit, physical and mineral soil properties, Medvednica Nature Park 